\title{
LA SITUACIÓN IMAGINARIA COMO ELEMENTO ESENCIAL DEL JUEGO DE ROLES SOCIALES EN LA EDAD PREESCOLAR ${ }^{1}$
}

\author{
The Imaginary Situation as an Essential Element of Social \\ Role-Play in Preschool Children
}

\author{
Claudia Ximena González-Moreno²
}

Recibido: 2017-11-11 Aceptado: 2018-09-17

\begin{abstract}
Resumen: Se analiza la situación imaginaria como elemento esencial de una experiencia de juego con un grupo de 20 niños preescolares entre los 5 y 6 años. Los niños tenían la posibilidad de crear imágenes mentales y representarlas a través de acciones. La experiencia sse desarrolló en un aula de una institución educativa pública en la ciudad de Bogotá, Colombia. Esta experiencia fue constituida y analizada de manera reflexiva desde la perspectiva de la psicología histórico-cultural. Los resultados muestran que las situaciones imaginarias son inicialmente promovidas por el adulto y después los mismos niños las expresan simbólicamente mediante su propia iniciativa. Se destaca la utilización de medios materializados, perceptivos y verbales como apoyo a la comprensión y expresión simbólica de los niños en el juego.
\end{abstract}

Palabras clave: educación de la primera infancia, desarrollo infantil, juego, imaginación, símbolos.

\begin{abstract}
The imaginary situation is analyzed as an essential element of a gaming experience with a group of 20 preschool children between 5 and 6 years old. The children had the possibility of creating mental images and of representing them through actions. The experience was developed in a classroom of a public educational institution in the city of Bogotá, Colombia. This experience was developed and analyzed reflexively from the perspective of historical-cultural psychology. The results show that the imaginary situations are initially promoted by the adult and then the children themselves express them symbolically on their own initiative. It highlights the use of materialized, perceptive and verbal media as support for the understanding and symbolic expression of children in the play.
\end{abstract}

Keywords: early childhood education, child development, play, imagination, symbols.
Para citar este artículo en APA: González-Moreno, C. (2019). La situación imaginaria como elemento esencial del juego de roles sociales en la edad preescolar. Revista de Psicología Universidad de Antioquia, 10(2), 75-101. DOI: 10.17533/ udea.rp.v10n2a04
Artículo de investigación. Hace parte de los análisis realizados en la investigación de la tesis doctoral "El juego de roles sociales como medio de formación de la función simbólica en nińos preescolares", en la Universidad Iberoamericana de Puebla-México.

2. Doctora en Educación. Estudiante del Programa Postdoctoral de Investigación en Ciencias Sociales, Niñez y Juventud de la Universidad de Manizales. Profesora de la Pontificia Universidad Javeriana, Bogotá, Colombia. Correo: clauxigo@hotmail. com; http://orcid.org/0000-0001-8099-860 


\section{Introducción}

La situación imaginaria se refiere a la posibilidad que desarrolla el niño de imaginar que es otro personaje y, por ende, realiza acciones en correspondencia con el rol que está representando, para lo cual crea en su mente diversas posibilidades que ejecuta con acciones mediante el uso de signos en los niveles materializado (González-Moreno y Solovieva, 2015; Solovieva, González-Moreno y Quintanar, 2015), perceptivo (González-Moreno, Solovieva y Quintanar, 2016; Solovieva, González-Moreno y Quintanar, 2016) y verbal (Solovieva y González-Moreno, 2016). En el nivel materializado el niño usa objetos como sustitutos de otros e inventa objetos imaginarios con sus acciones gestuales y corporales. En el nivel perceptivo el niño representa mentalmente un objeto o símbolo y después ejecuta acciones pictóricas en las que tiene la intención de que los otros participantes del juego comprendan su funcionalidad. En el nivel verbal el niño usa palabras para representar situaciones simbólicas.

Las situaciones imaginarias surgen aproximadamente desde los 3 años de edad en el juego de roles sociales. Éstas aparecen sólo si el adulto las introduce. Hay evidencia empírica que señala que estas situaciones imaginarias surgen cuando el niño ha participado en actividades previas con objetos - manipulación inespecífica de objetos de 6 a 12 meses—, en juego objetal — de 1 a 3 años—, en juego simbólico —entre 1.5 a 2 años—,en juego de roles sociales y en juego narrativo -3 a 6 ańos- (Hakkarainen y Bredikyte, 2015). La importancia teórica de pensar el juego de roles sociales y su relación con las situaciones imaginarias reside en que posibilitan la transformación del pensamiento hacia formas más complejas.

Lindqvist (2003) propone la creación de situaciones imaginarias en el juego en las que los niños tienen la posibilidad de identificarse con las acciones de los personajes que, por lo general, implican ayudar a los otros participantes y las representan. Los adultos son pares de los niños y conjuntamente crean nuevos problemas, proponen nuevos retos y obstáculos que son resueltos por los participantes en la actividad para que el juego continúe (Bredikyte, 2011). El juego puede ser enriquecido a través de diálogos compartidos entre el adulto y 
los niños (González-Moreno, 2016; 2018). Esto significa que hay intercambio comunicativo de ideas entre todos los participantes del juego. Estas ideas se materializan con palabras durante el juego, en el cual se representan diversas acciones que se imaginan.

Según Vigotsky (1995), el juego comienza cuando aparece una situación imaginaria. La situación imaginaria permite crear mundos imaginarios en el juego y surge en la interacción entre un grupo de nińos y uno o varios adultos (Lindqvist, 1995). El adulto tiene un rol activo al crear estos mundos imaginarios en el juego porque participa como cojugador (Hakkarainen y Bredikyte, 2015). Asimismo, para Vigotsky (1991) la situación imaginaria aparece en el ámbito del desarrollo psíquico, cuando un niño se independiza de su propia percepción y empieza a crear y representar situaciones diversas con sus acciones y su lenguaje. El lenguaje se usa para representar significados compartidos.

Las situaciones imaginarias adquieren una función muy importante en el desarrollo de los niños, pues se hace medio de ampliación de su experiencia porque les permite imaginarse y representarse aquello que no han visto, aquello que en su experiencia personal directa no ha tenido lugar (Vigotsky, 1967; 1999). Es así como los niños combinan diversas imágenes mentales que se materializan con el uso de objetos imaginarios, gestos, expresiones faciales y corporales, acciones imaginarias, y con el uso de expresiones verbales que incluyen transformaciones de sus ideas.

Una característica de las situaciones imaginarias es que los niños actúan de acuerdo con las ideas que comparten de manera interactiva y no según la realidad externa, es decir, según su uso cultural —objetos que ven—, lo cual significa que los niños ven los objetos pero actúan con ellos de manera diferente en relación con lo que ven (Bodrova, 1998; 2008). Los niños actúan con independencia respecto a lo que ven de manera concreta (Vigotsky, 1967). Por ello, se afirma que la emergencia de las situaciones imaginarias señala la aparición de nuevas formas del pensamiento abstracto en las que se usan signos y símbolos.

Las situaciones imaginarias sirven como medio para la creación de símbolos - por ejemplo, el uso de un círculo rojo indica protección, como si fuera un escudo-, además permiten experimentar y comunicar la propia y 
compartida comprensión del mundo (Bredikyte, 2011). Por esta razón, en las situaciones imaginarias es central la dialéctica de la comunicación entre los niños y el adulto. Esta forma de comunicación dinamiza la relación dialógica e interactiva entre los participantes del juego, espacio donde se hacen interpretaciones particulares del mundo (Lindqvist, 1995).

Otra característica de las situaciones imaginarias se refiere a que surgen en una interacción dinámica dada entre la propuesta de signos materializados, perceptivos y verbales en el juego. Esto significa que en el juego los niños tienen la posibilidad de realizar acciones imaginarias como si tuvieran objetos diversos, a la vez que pueden proponer signos gráficos — dibujos— para resolver un problema y con el lenguaje crean historias fantásticas que representan.

Una característica adicional de las situaciones imaginarias en el juego se refiere a que permiten pensar en los sentimientos de alguien más que no sea el niño mismo (Brill, 2004). De ese modo, las situaciones imaginarias contribuyen a que el nińo piense en el otro, que se conozca al manifestarse para el otro, a través del otro y con la ayuda del otro. Él abre sus ojos a su propia realidad y a la realidad del otro, lee, reconoce y descubre al otro en su experiencia de juego, en el diálogo compartido. En el juego otro sale a su encuentro. Por ello, se afirma que las situaciones imaginarias contribuyen con el desarrollo de la autorregulación del comportamiento y las emociones (Vigotsky, 1978), así como con la solución de problemas que surgen en el juego. Al participar en roles diversos dentro de las situaciones imaginarias del juego los nińos pueden expresar diferentes tipos de emociones positivas — amabilidad, bondad, dulzura, solidaridad, honestidad, respeto-y negativas — frustración—, lo que les permite ganar confianza en sí mismos y en los demás (Bredikyte, 2011). A su vez, en el juego los niños pueden predecir las acciones de los demás porque se ponen en el lugar del otro. En consecuencia, en el juego el niño siempre se comporta más allá de su edad promedio, por encima de su comportamiento diario, tal y como plantea Vigotsky $(1978,1995)$.

Por lo anterior, resulta novedosa la aportación que se presenta en este artículo para la población de América Latina porque posibilita generar transformaciones dentro del aula de clase con respecto a las actividades que se hacen con los niños en edad preescolar. En este artículo se hace el análisis de 
la situación imaginaria como elemento esencial del juego de roles sociales en la edad preescolar a partir de una experiencia desarrollada con un grupo de niños preescolares.

\section{Método}

En esta investigación se aplicó el método genético-experimental propuesto por L. S. Vigotsky (1995). Este método pretende estudiar los cambios en el desarrollo de las situaciones imaginarias creadas en el juego durante su realización; además, estudia la formación de las acciones intelectuales por etapas (Galperin, 1981). Al principio la nueva acción es externa y se apoya de objetos externos realizando manipulaciones externas con ellos, lo cual está referido al nivel de desarrollo psicológico, es decir, la realización de la acción (González-Moreno y Solovieva, 2014). Aquí se considera el desarrollo alcanzado por el niño y el desarrollo potencial con orientación del adulto en la actividad.

La tarea del investigador consiste en formar la acción con determinadas características que faciliten su transformación en la ejecución durante el juego: ya sea usando objetos, usando sustitutos de objetos, gestos representativos, objetos imaginarios, medios simbólicos diversos — dibujos - y el lenguaje — sobre la base lingüística de la acción-. Estas características se refieren específicamente a la orientación, el carácter reflexivo y flexible.

Igualmente, parte del papel de investigador consiste en reconstruir y reorganizar la actividad psíquica, en síntesis, lograr un efecto desarrollante en el sujeto. Este método enfatiza una intervención activa del investigador con el objetivo de formar la función psíquica que está estudiando (Montealegre, 1998, p. 263).

\section{Participantes}

En este estudio participaron 20 nińos entre los 5 y 6 años del último grado de preescolar, de una institución educativa distrital pública de la ciudad de Bogotá, en condiciones de vulnerabilidad, de los cuales 9 son niñas y 11 niños 
con una edad media de 5.1 años. La elección de los participantes fue efectuada al azar. En la presente investigación la vulnerabilidad de la población se caracteriza por la presencia de condiciones de extrema pobreza y bajos índices de escolaridad de los padres de los niños que hicieron parte del estudio. La aplicación de las sesiones de intervención fue concretada dentro del horario de actividades escolares de los nińos en la institución educativa. El trabajo con los nińos lo realizó una investigadora experta en desarrollo psicológico infantil.

En la tabla 1 se presenta el nivel de educación de las madres y los padres de los niños del estudio.

Tabla 1. Nivel de educación de la madre y el padre

\begin{tabular}{|l|c|c|}
\hline \multicolumn{1}{|c|}{ Nivel de educación } & Madres & Padres \\
\hline Primaria & 8 & 9 \\
\hline Bachillerato sin terminar & 9 & 8 \\
\hline Técnico & 3 & 3 \\
\hline
\end{tabular}

En la tabla 2 se muestra la ocupación de las madres y los padres.

Tabla 2. Ocupación de la madre y el padre

\begin{tabular}{|l|l|l|}
\hline \multicolumn{1}{|c|}{ Ocupación } & Madres & \multicolumn{1}{c|}{ Padres } \\
\hline Ama de casa & 14 & 0 \\
\hline Personal doméstico & 4 & 0 \\
\hline Vendedor de almacén & 2 & 6 \\
\hline Vendedor ambulante & 0 & 4 \\
\hline Conductor & 0 & 7 \\
\hline Obrero & 0 & 3 \\
\hline
\end{tabular}

\section{Procedimiento}

La intervención se realizó en 130 sesiones de juego. Cada sesión de juego tenía una duración de dos horas y el adulto conversaba dialógicamente con el grupo de niños. Esta conversación permitía introducir el tema, los roles y los 
objetos que se iban o no a utilizar. Después cada niño asumía un rol y lo representaba por medio de acciones simbólicas imaginarias. Al finalizar se realizaba una reflexión en relación con la situación de juego.

La experiencia de juego se desarrolló en un aula de clase con niños de último nivel de preescolar. Cada sesión de juego fue grabada con autorización de la institución educativa y de los padres de los niños. En la tabla 3 se presentan las etapas de juego consideradas en esta investigación. Estas etapas de juego fueron diseñadas específicamente para este estudio a partir de las necesidades de desarrollo psicológico de los niños.

Tabla 3. Etapas del juego de roles

\begin{tabular}{|l|l|}
\hline \multicolumn{1}{|c|}{ Etapas del juego } & \multicolumn{1}{c|}{ Descripción } \\
\hline $\begin{array}{l}\text { Etapa 1. Juego de roles sociales con el uso de ob- } \\
\text { jetos. } \\
\text {-30 sesiones de juego- }\end{array}$ & $\begin{array}{l}\text { - Se utilizan objetos en la representación de los } \\
\text { roles. }\end{array}$ \\
\hline $\begin{array}{l}\text { Etapa 2. Juego de roles sociales con sustitutos ob- } \\
\text { jetales. } \\
\text {-30 sesiones de juego- }\end{array}$ & $\begin{array}{l}\text {-Se utilizan sustitutos de objetos en la representa- } \\
\text { ción de los roles. }\end{array}$ \\
\hline $\begin{array}{l}\text { Etapa 3. Juego de roles sociales con uso de objetos } \\
\text { y sustitutos objetales en varios tipos de situaciones }\end{array}$ & $\begin{array}{l}\text { - Se utilizaron objetos y sustitutos de objetos en la } \\
\text { representación de los roles. }\end{array}$ \\
\hline $\begin{array}{l}\text { Etapa sesiones de juego- Juego de roles sociales con incremento de } \\
\text { iniciativa y propuesta de juegos nuevos. }\end{array}$ & $\begin{array}{l}\text { - En esta etapa de juego los niños proponen situa- } \\
\text { ciones diversas de juego y asumen roles. }\end{array}$ \\
\hline $\begin{array}{l}\text { Etapa 5. Juego de roles sociales narrativo. } \\
\text {-20 sesiones de juego- }\end{array}$ & $\begin{array}{l}\text { - En esta etapa de juego los niños, conjuntamente } \\
\text { con el adulto, construyen historias en las que se } \\
\text { combinaban elementos de la realidad y la imagi- } \\
\text { nación, y cada uno representa un rol. }\end{array}$ \\
\hline
\end{tabular}

\section{Consideraciones éticas}

Este estudio se hizo dentro de las normas éticas que tienen por base la Declaración de Helsinki, con consentimiento informado avalado por el comité ético del Doctorado Interinstitucional en Educación de la Universidad Iberoamericana de Puebla, el cual valoró la protección de los derechos fundamen- 
tales de los niños y de las instituciones educativas, respetando las exigencias legales y siendo conscientes de su responsabilidad ante la sociedad.

\section{Resultados}

Los resultados se presentan haciendo el análisis de la situación imaginaria como elemento esencial del juego de roles sociales en la edad preescolar. Con las situaciones imaginarias los niños tenían la posibilidad de imaginar tanto su propio rol como el rol de los demás, los objetos que podrían usar, las acciones que podrían representar, el escenario en el que se podría desarrollar el juego, el resultado de sus acciones y las relaciones causales de sus acciones.

En la tabla 4 se ilustra la transformación de las situaciones imaginarias en el juego de roles sociales considerando cada una de sus etapas. En esta tabla se observa que poco a poco las situaciones imaginarias van haciendo que se vuelva complejo el juego porque se pasa de las acciones imaginarias aisladas a la iniciativa, en la que los niños proponen las situaciones imaginarias por su propio deseo. Además, se observa la progresión en el juego y cómo los niños actúan en la situación imaginaria; por ejemplo, al inicio se presentan acciones imaginarias aisladas, después surgen secuencias de acciones imaginarias. De la misma manera, las situaciones imaginarias son representadas de manera perceptiva antes y durante el juego.

Estas situaciones imaginarias posibilitan que los niños se pongan en el lugar del otro y consideren sus sentimientos, se observan cambios de actitudes de los roles al considerar la perspectiva del otro, surgen situaciones imaginarias desplegadas en el tiempo - motivación por continuar ejerciendo acciones interactivas con otros roles-. Igualmente, las situaciones imaginarias posibilitan la solución de problemas de manera conjunta en el juego y surge el uso del lenguaje narrativo enriquecido a través de la interacción con otros roles en las situaciones imaginarias creadas. 
Tabla 4. Transformación de las situaciones imaginarias en el juego

\begin{tabular}{|l|l|l|l|l|l|}
\hline \multirow{2}{*}{ Categorías de análisis } & \multicolumn{5}{c|}{ Etapas del juego } \\
\cline { 2 - 7 } & $\begin{array}{c}\text { Etapa 1 } \\
\text { 30 sesiones }\end{array}$ & $\begin{array}{c}\text { Etapa 2 } \\
\text { 30 sesiones }\end{array}$ & $\begin{array}{c}\text { Etapa 3 } \\
\text { 30 sesiones }\end{array}$ & $\begin{array}{c}\text { Etapa 4 } \\
\text { 20 sesiones }\end{array}$ & $\begin{array}{c}\text { Etapa 5 } \\
\text { 20 sesiones }\end{array}$ \\
\hline Acciones imaginarias aisladas. & - & $\sqrt{n}$ & - & - & - \\
\hline $\begin{array}{l}\text { Surgen las secuencias de acciones } \\
\text { imaginarias. }\end{array}$ & - & - & $\sqrt{ }$ & $\sqrt{ }$ & $\sqrt{ }$ \\
\hline $\begin{array}{l}\text { Iniciativa en la propuesta de situa- } \\
\text { ciones imaginarias. }\end{array}$ & - & - & - & $\sqrt{ }$ & $\sqrt{ }$ \\
\hline $\begin{array}{l}\text { Situaciones imaginarias que son } \\
\text { representadas de manera percepti- } \\
\text { va antes y durante el juego. }\end{array}$ & - & - & - & $\sqrt{ }$ & $\sqrt{ }$ \\
\hline $\begin{array}{l}\text { Situaciones imaginarias que posi- } \\
\text { bilitan que los niños se pongan en } \\
\text { el lugar del otro y consideren sus } \\
\text { sentimientos -cambios de acti- } \\
\text { tudes de los roles al considerar la } \\
\text { perspectiva del otro-. }\end{array}$ & - & - & - & $\sqrt{ }$ & $\sqrt{ }$ \\
\hline $\begin{array}{l}\text { Situaciones imaginarias desplega- } \\
\text { das en el tiempo - motivación por } \\
\text { continuar realizando acciones inte- } \\
\text { ractivas con otros roles-. }\end{array}$ & - & - & - & $\sqrt{ }$ & $\sqrt{ }$ \\
\hline $\begin{array}{l}\text { Situaciones imaginarias que posi- } \\
\text { bilitan la solución de problemas de } \\
\text { manera conjunta en el juego. }\end{array}$ & - & - & - & $\sqrt{ }$ & $\sqrt{ }$ \\
\hline $\begin{array}{l}\text { Uso del lenguaje narrativo enri- } \\
\text { quecido en interacción con otros } \\
\text { roles en las situaciones imaginarias } \\
\text { creadas. }\end{array}$ & - & - & - & - & \\
\hline
\end{tabular}

$\checkmark$ : presencia estable y arraigada;

_: ausencia.

En la tabla 5 se presentan algunos ejemplos de elementos que hacen parte de las ejecuciones de los niños en las situaciones imaginarias en el juego de roles sociales. Estos elementos permitieron el ir haciendo más complejas las etapas de los juegos de roles. 
Tabla 5. Elementos que hacen parte de las situaciones imaginarias

\begin{tabular}{|c|c|}
\hline $\begin{array}{c}\text { Elementos de } \\
\text { las situaciones } \\
\text { imaginarias }\end{array}$ & Descripción \\
\hline $\begin{array}{l}\text { Propuesta de } \\
\text { objetos } \\
\text { imaginarios }\end{array}$ & $\begin{array}{l}\text { El nińo usa palabras y acciones para representar objetos en el juego. Por ejemplo, } \\
\text { el niño dice que es necesario nadar para encontrar un tesoro en el fondo del mar e } \\
\text { invita a sus compañeros a nadar, para lo cual mueven sus manos como si se estuvieran } \\
\text { poniendo un traje antes de lanzarse al agua. }\end{array}$ \\
\hline $\begin{array}{l}\text { Propuesta de } \\
\text { ambientes } \\
\text { imaginarios }\end{array}$ & $\begin{array}{l}\text { El niño usa palabras y acciones para crear y representar lugares diversos según la si- } \\
\text { tuación de juego. Por ejemplo: un bosque profundo lleno de árboles, un barco pirata. }\end{array}$ \\
\hline $\begin{array}{l}\text { Propuesta de } \\
\text { situaciones } \\
\text { mágicas de } \\
\text { aventura }\end{array}$ & 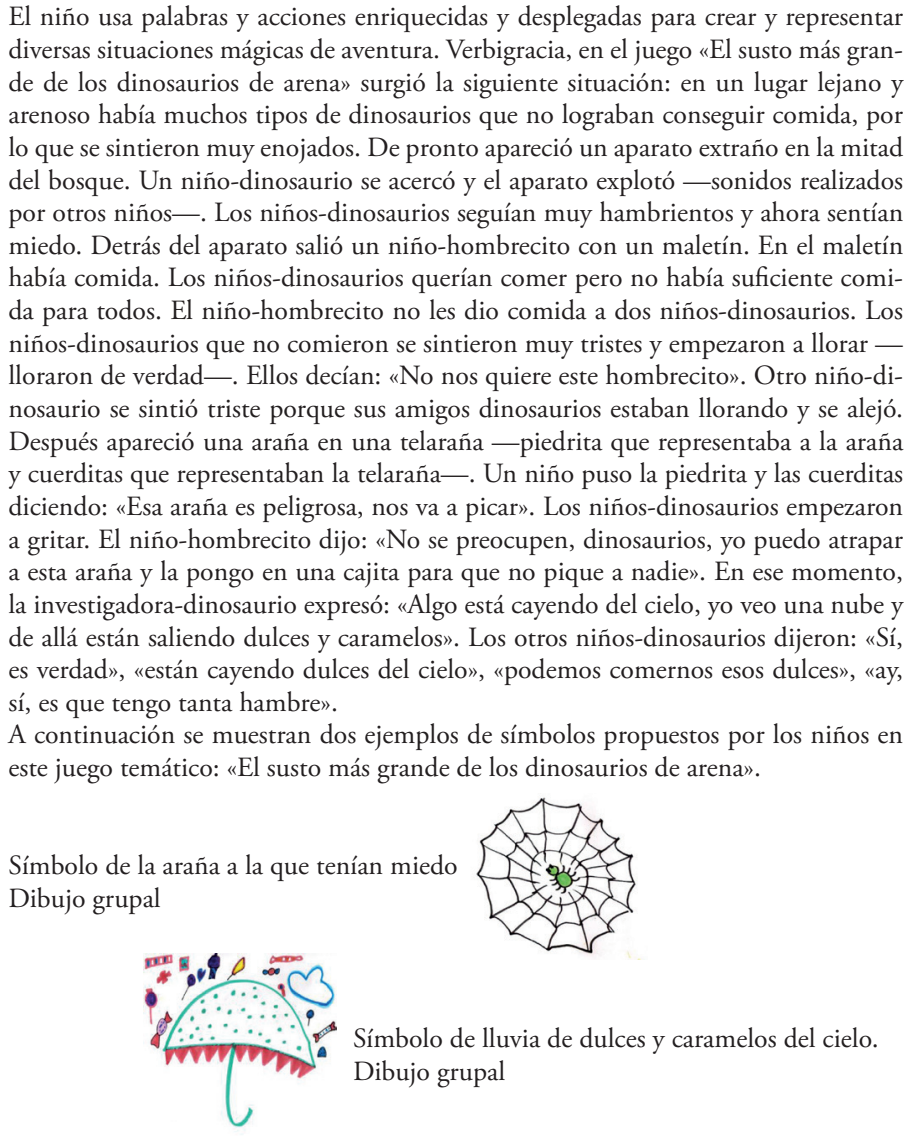 \\
\hline $\begin{array}{l}\text { Propuesta de ro- } \\
\text { les imaginarios }\end{array}$ & $\begin{array}{l}\text { El nińo propone roles que hacen parte de la fantasía. Por ejemplo, una princesa } \\
\text { ratona que quería aprender a volar. }\end{array}$ \\
\hline
\end{tabular}


En la tabla 6 se presentan las características de las situaciones imaginarias en el juego de roles.

\section{Tabla 6. Caracteristicas de las situaciones imaginarias en el juego de roles}

\begin{tabular}{|l|l|}
\hline \multicolumn{1}{|c|}{ Características } & \multicolumn{1}{|c|}{ Descripción } \\
\hline Interacciones comunicativas creativas & $\begin{array}{l}\text { Los participantes del juego interactuaron haciendo aportacio- } \\
\text { nes comunicativas novedosas que enriquecían la situación ima- } \\
\text { ginaria con elementos sorpresivos e inesperados. De esta forma } \\
\text { la experiencia adquirió un sentido y significado que se transfor- } \\
\text { mó en acciones. Las interacciones comunicativas creativas per- } \\
\text { mitieron la cooperación activa entre los participantes del juego } \\
\text { en la díada hablante-escucha y promovieron las interacciones } \\
\text { prolongadas. }\end{array}$ \\
\hline Habla que caracteriza al rol & $\begin{array}{l}\text { Los niños cambiaron la entonación de la voz cuando asumían } \\
\text { un rol en el juego de acuerdo con la situación imaginaria. }\end{array}$ \\
\hline $\begin{array}{l}\text { Solución de problemas considerando } \\
\text { diversas perspectivas }\end{array}$ & $\begin{array}{l}\text { Los niños podían explorar soluciones alternativas a los proble- } \\
\text { mas del juego. }\end{array}$ \\
\hline $\begin{array}{l}\text { Toma de decisiones que benefician } \\
\text { al colectivo de los participantes del } \\
\text { juego }\end{array}$ & $\begin{array}{l}\text { Los niños tenían la posibilidad de tomar una posición propia } \\
\text { desde la postura del otro. }\end{array}$ \\
\hline Expresión de nuevas ideas & $\begin{array}{l}\text { Los nińos podían expresar ideas y compartir opiniones que sur- } \\
\text { gían en cada momento del juego. }\end{array}$ \\
\hline $\begin{array}{l}\text { Uso de medios culturales - } \\
\text { símbolos- en las interacciones } \\
\text { comunicativas del juego }\end{array}$ & $\begin{array}{l}\text { Los medios culturales que los niños usaron en sus interacciones } \\
\text { comunicaban nuevas ideas que poco a poco se volvieron más } \\
\text { complejas; por ejemplo, cuando los niños usaron pinturas má- } \\
\text { gicas para construir el país de los sueńos mágicos, de ese modo, } \\
\text { a través de la creación de un mundo imaginario lograron cum- } \\
\text { plir sus deseos. }\end{array}$ \\
\hline
\end{tabular}

Al comunicar a los demás las diversas situaciones imaginarias en la actividad colectiva de juego los niños adquirieron consciencia de las nuevas formas de creación simbólica, lo que se reflejó en sus interacciones sociales.

Verbigracia, en el juego «El gran milagro de los héroes y villanos» los niños crearon imágenes fantásticas que se referían al "gran milagro» que se produjo durante el encuentro de niños-héroes y niños-villanos en un lugar mágico llamado «Bosque encantado». El «gran milagro» consistió en que lograron hablar con los animales del bosque. La fantasía estuvo extraordinariamente dirigida desde el principio hasta el fin, lo cual significa que los niños se daban cuenta 
de los fines que perseguía esa actividad. El objetivo que tenían los participantes del juego era producir un milagro en él, es decir, los niños deseaban provocar un evento mágico maravilloso. En esta sesión de juego había niños-héroes, niños-villanos y niños-animales - los niños usaron títeres de animales para hablar a través de ellos-. En el cuadro 1 se presenta un ejemplo de conversación dialógica creativa en la que los nińos adquirieron consciencia de las nuevas formas de creación simbólica. Por ejemplo, en el caso de producir un evento mágico maravilloso los niños participaron de forma secuencial, enriqueciendo las interacciones comunicativas con el uso de expresiones verbales.

\section{Cuadro 1. Ejemplo de conversación dialógica creativa en la planeación del juego «El gran milagro de los héroes y villanos»}

\footnotetext{
Nińo (aI). - Yo quiero ser un héroe.

Niño (CI). - Los héroes son buenos.

Nińo (JG). - Y tienen superpoderes.

Adulto.-_Cómo se imaginan los superpoderes?
}

Niño (JD). - A mí me gusta ser veloz para correr muy rápido y para imaginar que vuelo más rápido.

Niño (AI). - Yo soy fuerte — señala los músculos de sus brazos - y puedo levantar lo que quiera que sea tan pesado.

Nińo (HS). - Como un edificio.

Niño (AI). - -Sí, como un edificio.

Nińo (Hs). - Yo quiero tener el poder de la luz para iluminar todo lo que esté oscuro.

Nińa (EC). - Yo quiero tener el poder de ser amorosa con muchos corazones.

Nińo (RM). - Yo quiero tener el poder del agua.

Niño (JL). - Para hacer llover.

Adulto.- ¿YY qué pasaría si aparecen los villanos?

Nińo (DP). - Que podrían hacer algo mal.

Adulto.- ¿ ¿Será que si los villanos hacen algo mal, los superhéroes vienen a ayudar?

Niño (JL). - Sí.

Niño (AI). - Podría ser un milagro mágico.

Adulto.-_Cuál podría ser ese milagro mágico?

Niña (мv). - Mmm, que los pajaritos estaban tristes y lloraban y lloraban porque estaban atrapados en una jaula y no podían volar.

Nińo (AL). - Digamos que los supervillanos encerraban a los pajaritos en una jaula.

Nińo (AI). - Ah, y los héroes los rescataban.

Nińa (Mv). - Y ahora los pajaritos estaban muy felices porque podían ir a donde querían.

Niña (EC). - Y también digamos que como los pajaritos estaban felices entonces les daban las gracias a los héroes. 
Niño (CI). — Y los pajaritos ayudaban a los héroes a que pudieran hablar con ellos.

Adulto.-Y si los villanos se dan cuenta ¿qué creen que podrían hacer?

Nińa (кG). - Se pondrían muy tristes.

Niña (AD). - Sería lo más triste de la vida que los héroes sí puedan hablar con los pajaritos y los villanos no.

Nińo (CI). - Tengo una idea, entonces los villanos también podrían hablar con los pajaritos.

Niño (AI). - Sí, pero sólo si hacen algo bueno y no los vuelven a encerrar.

Adulto.-Entonces ese podría ser parte del milagro: que los héroes y los villanos pueden hablar con los pajaritos. ¿Qué símbolos podríamos usar?

Niño (AI). - Yo podría hacer el símbolo de la fuerza con unos músculos de fuerte.

Niño (JD). - Yo quiero dibujar una flecha que muestre que soy tan rápido como un rayo.

Niño (AI). —Con mi fuerza del símbolo yo puedo abrir las jaulas en donde están los pajaritos.

Nińo (HS). - Yo haré rayitos de sol para mostrar que hay mucha luz por todas partes y para que los pajaritos se sientan calientitos.

Nińa (EC). - Yo puedo dibujar corazones de amor para ayudar a que los villanos sigan siendo muy buenos con los pajaritos siempre.

Niño (вм). - A mí me gustaría hacer goticas de lluvia para mostrar que los arbolitos se pueden mojar y crecen más bonito.

Nińa (Mv). —Para que los pajaritos sientan alegría y puedan hacer sus nidos.

${ }^{*}$ La transcripción corresponde a lo que dicen los niños.

En el cuadro 2 se presenta un ejemplo de conversación dialógica creativa realizada durante el juego «El gran milagro de los héroes y villanos». Aquí se observa que el lenguaje verbal logró enriquecer de manera creativa el juego y las acciones imaginarias. Por ejemplo, los niños por iniciativa hicieron propuestas acerca de cómo unir sus poderes para salvar al planeta.

\section{Cuadro 2. Ejemplo de conversación dialógica creativa durante la ejecución del juego "El gran milagro de los héroes y villanos»}

Nińo (AI). - Tenemos que unir nuestros poderes.

Niña (Mv). - Si unimos nuestros poderes podemos salvar al planeta de los que quieren encerrar a los animalitos en jaulas.

Niño (HS). - Y para que por toda la vida podamos hablar con los pajaritos.

Niño (CI). - Y qué tal si los pajaritos nos enseñan el idioma de los otros animales.

Adulto.-Esa es una idea asombrosa, así podríamos hablar con todos los animales del bosque.

Nińo (JD). - Y los animales podrían seguir siendo nuestros amigos. 
Niño (JG). - Podríamos hacer el símbolo de hablar con un pico abierto.

Nińo (sB). - Sí, el piquito nos muestra que los pajaritos hablan con todos los animales su idioma.

Nińa (AD). - Yo estoy hablando con el conejo de orejas largas en lenguaje de conejo.

Nińo (JL). - Yo lo puedo entender, dice que quiere comer zanahorias y que lo que más le gusta de la vida es saltar.

Nińo (DP). - Yo quiero hablar con los perros, voy corriendo muy veloz para encontrar un perrito.

Nińo (CI). - Yo quiero hablar con todos los animales, y yo tenía una botellita con polvillos mágicos y podía hablar con todos los animalitos del bosque. Hola, pajarito; hola, perrito; hola, conejito, hola, ardillitas; hola, ositos.

Nińa (кс). - Hola, yo soy una ardillita y me gusta correr y correr por los árboles, yo vivo en ese huequito.

Nińa (KG). - Yo soy un osito y me duele mi patica porque me lastimé.

Nińo (CI). - Yo te puedo ayudar a revisar tu patita, ¿te duele?

Niña (KG). - Sí, auch.

Niño (CI). - Te voy a poner una hojita para que no te duela más.

Niña (AD). - Yo perdí a uno de mis hijos y estoy muy triste, es que era el más pequeñito de todos y no lo encuentro por ningún lado.

Nińo (AI). - Yo quiero ayudar a buscar a tu hijito. Héroes y villanos: tenemos una nueva misión. Este pajarito perdió a su hijito pajarito y está muy pero muy triste y llora todo el tiempo, tenemos que ayudarlo a buscar a su hijito perdido.

Adulto.—¿Cómo era tu hijito?

Nińa (AD).-Era muy pequeñito, de color azul y tenía una plumita azul muy larga.

Nińa (Mv).--Tengo una idea, tenemos que dividirnos para buscar al pajarito.

Nińo (AI). — Si, por aquí unos — señala a la derecha — y otros por allá — señala a la izquierda—.

Niño (CI). - Yo no encuentro nada.

Nińo (RM). - Pajarito azulito, ¿̨dónde estás?

Niño (sв). - Pajarito, pajarito, ven.

Nińa (EC). - Lo encontré y tiene un alita lastimada.

Niña (Mv). - No puede volar.

Nińo (JD). - Lo encontramos, encontramos al pajarito perdido, aquí, aquí, vengan aquí.

Nińo (AL). —Una tormenta está cerca.

Nińa (EC). - Ay, no tenemos con qué proteger a este pajarito.

Nińo (sB). - Yo encontré más pajaritos con el alita lastimada, ayúdenme, por favor

Adulto. - Empezaron a caer goticas de agua, va a llover muy fuerte.

Nińo (JD). - Podemos poner todos los símbolos de los superpoderes para hacer una cuevita rápido y llevar a los pajaritos allí mientras deja de llover.

Nińo (CI). - En la cueva apareció un jaguar feroz.

Nin̄o (AI). - No, es peligroso para los pajaritos.

Adulto.- Vamos todos por aquí, en silencio, para que el jaguar no nos vea.

Niño (RM). - El jaguar tiene algo debajo de sus patas. 
Adulto: parecen monedas de oro.

Niño (AI). - Podemos hablar con el jaguar.

Adulto.-Sí, podemos intentarlo.

Nińo (HS).—Asume otro rol. Él imagina ahora que es el jaguar y cambia su voz-. ¿Ustedes qué hacen aquí?, ¿̇se quieren llevar mi tesoro?

Nińo (CI). - No, sólo queremos proteger a nuestros amigos los pájaros de la gran tormenta.

Niño (Hs). - Mi tesoro estaba enterrado y cuando ustedes aparecieron aquí, las monedas empezaron a rodar por todos lados.

Adulto.- - Señor Jaguar, no nos vamos a llevar su tesoro, ni una sola moneda, se lo prometemos.

Nińa (EC). - Parece que ya terminó la tormenta.

Adulto.-Entonces podemos irnos.

Niño (Hs). - Se pueden ir por esa salida secreta.

Niño (CI). - Muchas gracias, seńor Jaguar.

Niña (MV). - Yo veo una cascada.

Adulto. - Sigamos la piedra de la cascada para regresar al bosque.

Niño (CI). - Vamos pajaritos, no tengan miedo.

Nińo (AI). - Lo logramos.

Adulto.-Ahora a celebrar.

*La transcripción corresponde a lo que dicen los nińos.

\section{Cuadro 3. Ejemplo de conversación dialógica creativa durante la reflexión final en el juego "El gran milagro de los héroes y villanos»}

Nińo (AI). - A mí me gustó que por primera vez los héroes y villanos éramos amigos.

Niño (HS). - Sí, y pudimos unir nuestras fuerzas.

Niño (EC). - Y nuestros superpoderes.

Nińa (Mv). - Y ayudamos a los animalitos del Bosque encantado.

Niño (CI). - Y como ayudamos a la mamá Pajarito podíamos entenderlos.

Nińo (AI). - Y podíamos hablar con los animalitos del bosque.

Adulto. - Y todo eso lo pudimos hacer porque a todos nos gustaban mucho los animalitos.

Niño (Js). -Sí.

Nińa (Mv). - Y no nos gustaba que estuvieran tristes o enfermos o encerrados.

Nińa (EC). - A mí me gustó mi símbolo de corazones porque podía recordar que siempre era amorosa con todos en el bosque encantado.

Nińa (MC). - A mí me gustó ser el pajarito chiquito porque me repararon mi alita y pude volar y encontré a mi mamita. 
Niño (JG). - A mí me gustó cuando unimos nuestros símbolos para evitar que la gran tormenta lastimara a los pajaritos.

Niño (HS). - A mí me gustó ser el jaguar del tesoro misterioso.

Nińo (AI). - A mí me gustó también que no nos rendimos ni por un momento.

Adulto.- $-\mathrm{Ni}$ ante la tormenta ni ante el jaguar.

*La transcripción corresponde a lo que dicen los niños.

En la figura 1 se muestra un ejemplo de expresión simbólica creativa de los niños, en la forma perceptiva, dentro del juego «El gran milagro de los héroes y villanos». Esta forma de expresión simbólica se presentó por iniciativa de los niños en la etapa de juego de roles narrativo. Aquí los símbolos que los niños proponían tenían la intencionalidad de representar los superpoderes: «veloz», «amoroso», «iluminar», «mojar», «fuerza», «hablar con los pajaritos». Además, los símbolos representaban el lugar que hacía parte del juego — «Bosque encantado»—, personajes del juego — «animales del bosque»—y acciones — «estar encerrado».

Figura 1. Ejemplo de expresión simbólica creativa en la forma perceptiva dentro del juego "El gran milagro de los héroes y villanos»

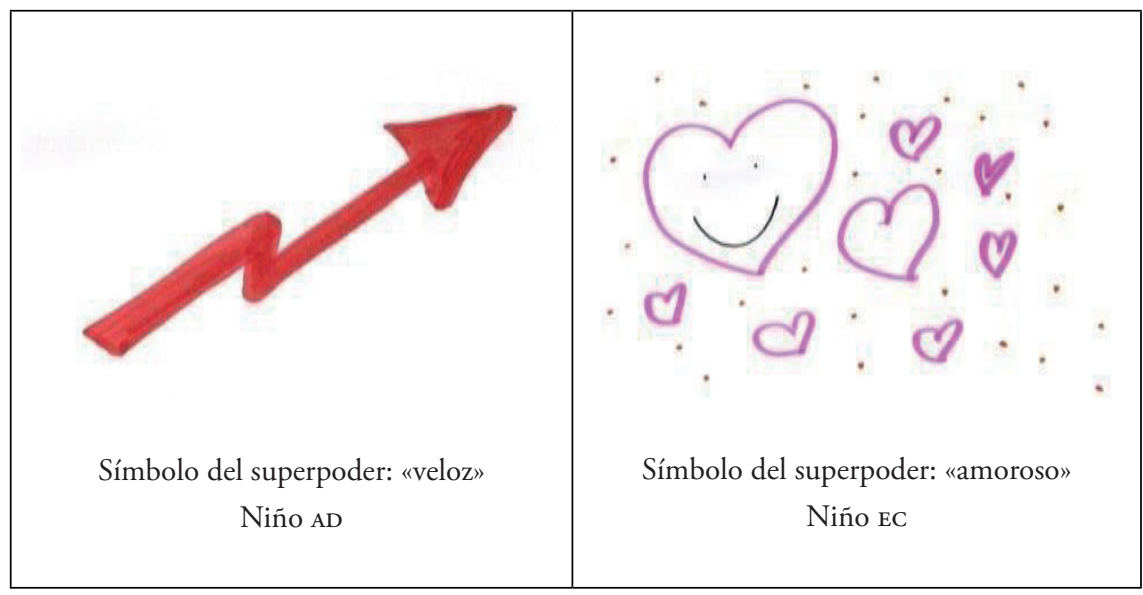




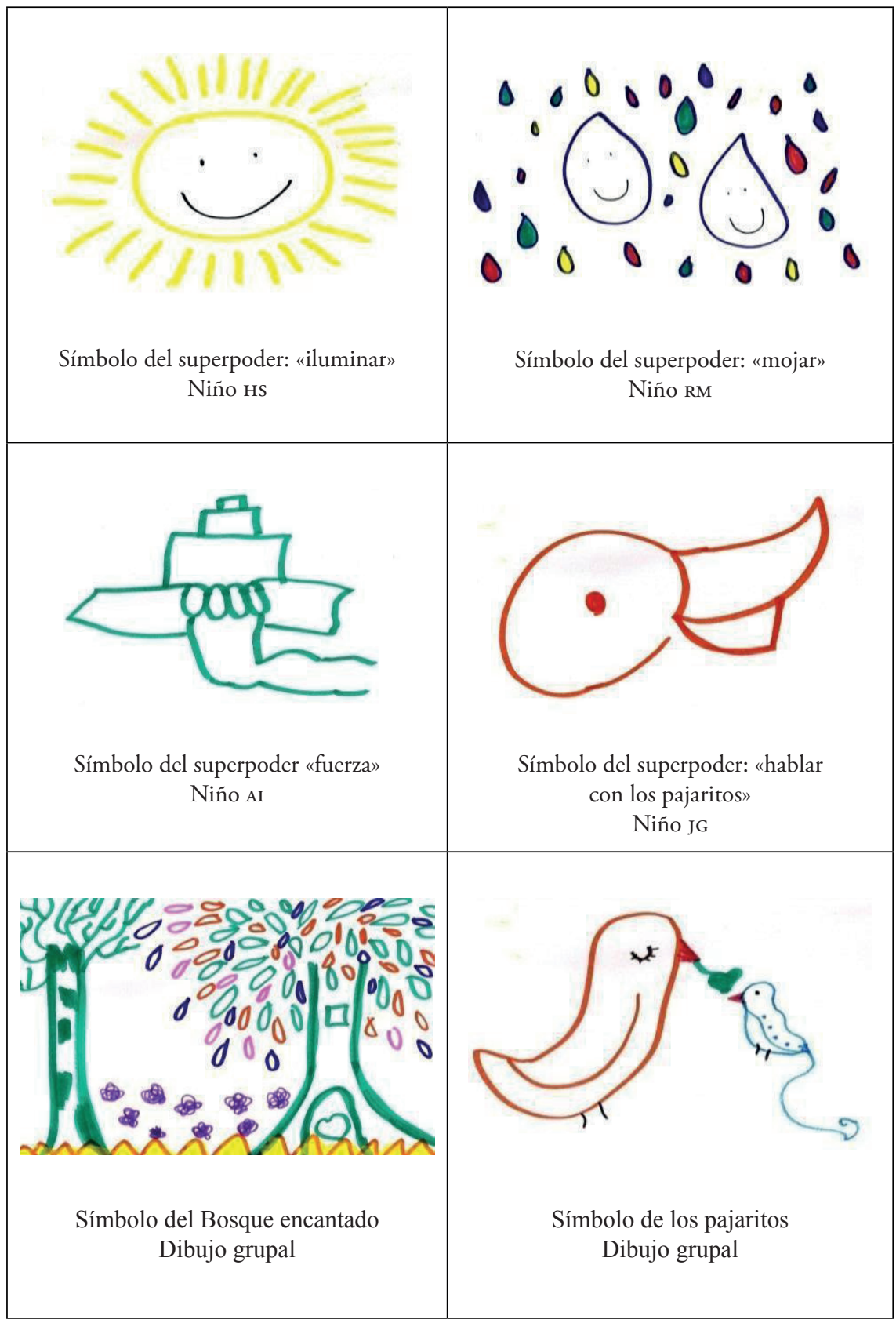




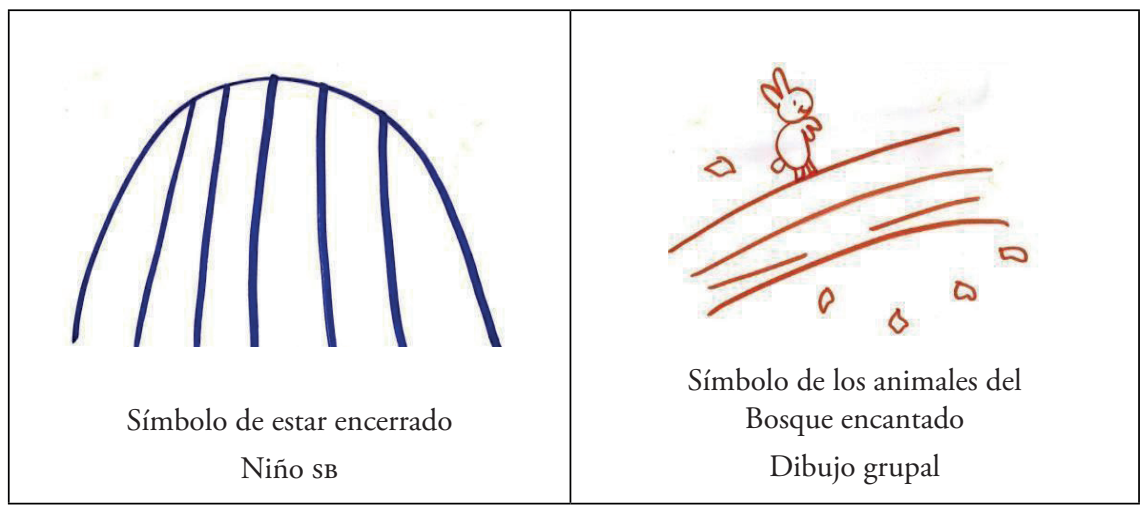

En las intervenciones del juego se observa que los niños empezaron a subordinar sus acciones a las situaciones imaginarias. Las situaciones imaginarias involucraron tanto los intereses como las emociones reales de los participantes. Esto implica que las situaciones imaginarias facilitaron la expresión de sentimientos reales.

Verbigracia, cuando un niño en el juego «La navidad» eligió ser «Santa Claus», las acciones-sentimientos correspondientes al rol se convirtieron en objeto de la actividad. En esta sesión de juego los niños sintieron el deseo de compartir y ayudar. El niño-Santa Claus expresó sentimientos de amor, ternura y bondad hacia los niños que iba a visitar para entregarles obsequios. El niño que eligió ser un reno expresó sentimientos de miedo cuando imaginó que estaba volando en el aire y llevaba una gran cantidad de obsequios. El niño-reno decía: «Este reno se va a caer porque pesan mucho estos obsequios, qué voy a hacer», su expresión gestual era de miedo real. En consecuencia, los niños experimentan sentimientos reales durante el juego. Ante esta situación el niño-Santa Claus dijo: «No tengas miedo, ya vamos a llegar a la casa del primer niño que nos envió la carta, allí vas a poder descansar». El niño-reno expresó: «Está bien». Cuando el niño-Santa Claus y el niño-reno imaginaron que llegaron a su destino, a la casa del primer niño - mediante una carta con símbolo de estrellita amarilla con sonrisa-, el niño-Santa Claus le dio un fuerte abrazo al niño-reno y le dijo: «Muy bien, lo hiciste, ahora vamos a entregarle el obsequio a nuestro primer niño». El niño-reno manifestó: «Gracias por el abrazo, me hizo sentir 
muy feliz y me dio valor para continuar volando — situación imaginaria— para cumplir con nuestra misión en esta gran noche de navidad».

En esta sesión de juego la misión del niño-Santa Claus consistía en entregarles los regalos a los niños con ayuda del niño-reno, sin embargo, en la casa de los niños sucedió algo inesperado. En la primera casa la bolsa con los regalos desapareció, por lo cual el niño-Santa Claus y el niño-reno tuvieron que buscar la bolsa mágica. En la segunda casa apareció un personaje malvado que se llevó al niño-Santa Claus y lo encerró en un calabozo. El niño-reno tuvo que ir a pedir ayuda. Los niños ayudantes de Santa Claus decidieron acompañar al niño-reno para rescatar al niño-Santa Claus. Ellos encontraron al niño-Santa Claus en una cueva secreta. El niño-reno decidió proponer el uso de pistas o signos especiales para que los niños-ayudantes lograran encontrar al niño-Santa Claus. Como pistas el niño-reno usó corazones rojos formando un camino. El adulto-ayudante dijo: «Miren, por aquí están los corazones del traje de Santa, si los seguimos lo podremos rescatar». Después de que los niños lograron rescatar al niño-Santa Claus y encerrar al personaje malvado decidieron acompañarlo para protegerlo. En la tercera casa el niño-reno se lastimó una pierna, entonces los niños-ayudantes de Santa Claus le pusieron un yeso — con pedazos de papel-y lo cargaron. En la figura 2 presentamos algunas formas de expresión simbólica creadas por los niños por iniciativa propia en el juego «La navidad».

Figura 2. Ejemplo de expresiones simbólicas en el nivel perceptivo dentro del juego "La navidad»

Santa Claus. Su bolsa de regalo - tiene forma de
balón de colores porque los niños dijeron que era
mágica y los colores eran los que le daban el poder de
ser mágica-y la carta de los niños.
Dibujo grupal




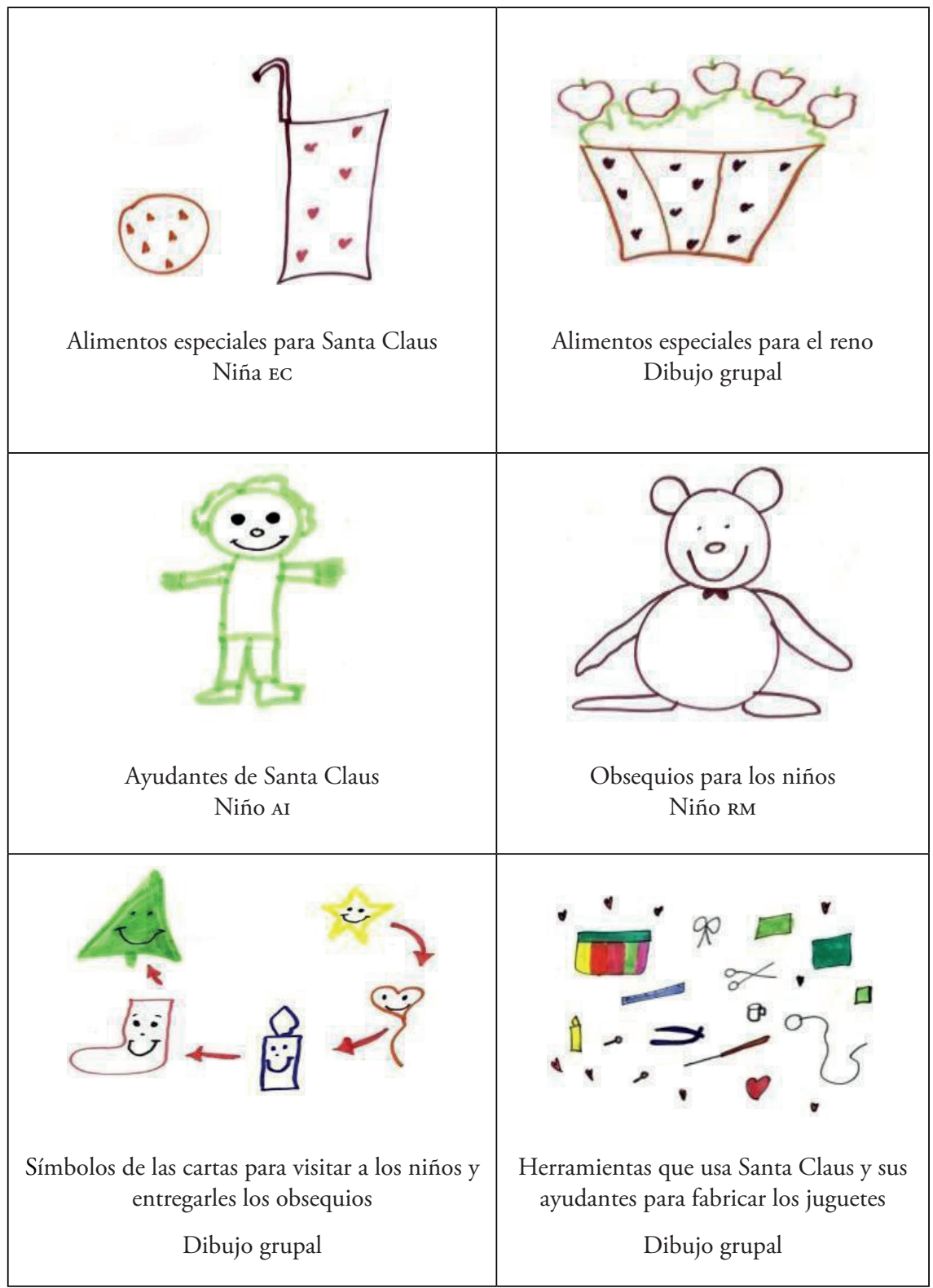




\section{Discusión}

La situación imaginaria es introducida por el adulto en el juego, ésta no surge por sí misma. Por esa razón, las situaciones imaginarias emergieron de la relación entre las acciones prácticas y las ideas de los participantes en la experiencia del juego de roles. Estas situaciones imaginarias permitieron crear mundos imaginarios compartidos y posibilitaron que los participantes expresaran inquietudes y tomaran decisiones. Se encontró que en la primera etapa de juego los niños usaban objetos concretos y en la segunda etapa la acción concreta se transformó en simbólica. Asimismo, en la segunda etapa de juego de roles surgieron las acciones imaginarias aisladas. En la tercera etapa del juego aparecieron las secuencias de acciones imaginarias. En la cuarta y quinta etapa de juego de roles emergió la iniciativa en la propuesta de acciones imaginarias mediante la utilización de medios simbólicos materializados, perceptivos y verbales. Sin embargo, es importante mencionar que en las sesiones de juego correspondientes a la última etapa los niños realizaban acciones en sus roles apoyándose fundamentalmente en medios perceptivos y verbales.

Se observaron cambios en los niños que participaron en este estudio, desde los niveles más bajos de desarrollo de las acciones simbólicas, hasta la situación imaginaria en el nivel alto de desarrollo de medios simbólicos y del juego de imaginación. Esto señala la importancia de cambiar las actividades que se realizan en la edad preescolar con los niños e introducir la actividad de juego, específicamente la actividad de juego de roles sociales. En este estudio se mostró de qué manera es posible transformar el nivel de desarrollo, incluso en condiciones de vulnerabilidad. Estos niños ahora tienen nuevas posibilidades de desarrollo, de interacción comunicativa y de aprendizaje.

Las situaciones imaginarias que se desarrollaron en el juego generaron transformaciones en los roles. De la misma manera, cuando los roles se fortalecieron en el juego se produjeron transformaciones enriquecidas en las situaciones imaginarias, como se observa en la figura 3. Durante estas transformaciones los participantes del juego consideraron diversas opciones para la solución de los problemas que se presentaban. En la toma de decisiones para 
la elección de alguna de estas opciones los niños usaron variados medios simbólicos de acuerdo con el sentido que le daban al juego.

Tanto para la creación de las situaciones imaginarias como para la representación de los roles los niños usaron medios simbólicos materializados, perceptivos y verbales. De ese modo, los participantes desplegaban sus acciones simbólicas en las interacciones con los otros roles y se identificaban emocionalmente con los demás sobre la base del sentido del juego.

Figura 3. Dinámica de relaciones entre las situaciones imaginarias y los roles

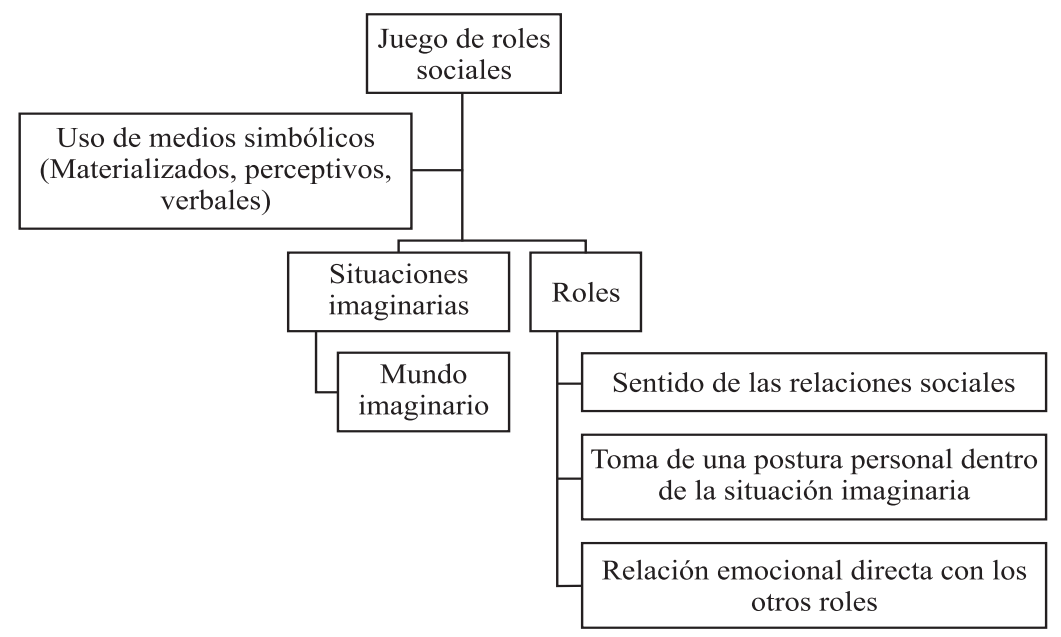

Los hallazgos obtenidos en esta investigación permiten realizar un análisis reflexivo de la situación imaginaria como elemento esencial del juego en niños de preescolar.

La primera reflexión se refiere a que las situaciones imaginarias constituidas con el uso del lenguaje promueven la originalidad de ideas en el colectivo de niños. Esto permitió satisfacer las necesidades emocionales, cognitivas y creativas de los niños porque pudieron expresar lo que sentían y pensaban. En esta experiencia de juego los objetos se convirtieron en lo que los niños querían. Más aún, en el juego los niños aprendieron a compartir sus ideas con los otros y a idear planes conjuntos. Para lograr esto, los niños en el juego aprendieron a escuchar las ideas de los otros y las enriquecieron con el uso del lenguaje. 
La segunda reflexión tiene que ver con el hecho de que cuando los niños proponían situaciones imaginarias en el juego lograban descubrir diferentes posibilidades para realizar acciones en los roles y, de esta manera, se fortalecían en la interacción con los otros roles. Esta forma de juego permitió la creación de situaciones de aventura en la que los participantes asumieron retos y resolvían problemas conjuntamente. Los niños aprendieron que pueden pensar independientemente de lo que ven físicamente. Además, el juego ayudó a los nińos a entender que las ideas pueden ser utilizadas para guiar el comportamiento porque les obligó a seguir las reglas sociales en la situación imaginaria, tal y como lo proponen Smith y Mathur (2009).

La tercera reflexión muestra que el uso de herramientas culturales le permitió a los niños dirigir su imaginación en el proceso de resolución de problemas, así como lo plantea Diachenko (2011). De allí surgió la imaginación creativa: los niños recurrían a su experiencia para inventar situaciones diversas en el juego de manera conjunta. Las situaciones imaginarias en el juego implicaron transformaciones en la experiencia de los niños, lo que les permitió actuar en un mundo seguro creado por ellos (Göncü, 1993; 2007). A su vez, la creación de una situación imaginaria eliminaba la frustración (Diachenko, 2011); por ejemplo, cuando un niño sentía miedo ante un personaje como un lobo enojado, el niño movilizaba la situación imaginaria como él quería en colaboración con los demás niños. Esto posibilitaba superar la frustración del niño, quien pasaba de no saber qué hacer porque sentía miedo a saber qué actitud asumir para lograr que el lobo fuera amigable.

El mundo imaginario se crea en la medida de las necesidades y deseos de los participantes del juego. En sí mismas las situaciones imaginarias que hacen parte de este mundo imaginario involucran reglas sociales de interacción, sin embargo dan la sensación de libertad, el único límite es la propia imaginación (Bredikyte, 2011, p. 143).

La cuarta reflexión hace referencia a que las situaciones imaginarias en el juego le dieron sentido a las actitudes de los niños al considerar la perspectiva del otro. Es decir, las situaciones imaginarias implicaron la habilidad para comprender las emociones de los demás. Esta habilidad se expresó a través del lenguaje verbal y no verbal. Los participantes del juego comprendieron que 
los deseos de los demás son diferentes de los propios, lo que implicó también la habilidad de hacer inferencias sobre el estado mental del otro.

Finalmente, se puede afirmar que las situaciones imaginarias posibilitan el desarrollo de habilidades como la solución de problemas de manera creativa y novedosa conjuntamente con los otros, la autorregulación emocional amplia, la reflexión respecto al comportamiento propio y al de los demás, o la toma de decisiones de acuerdo con el sentido de las relaciones sociales en el juego. Por consiguiente, con las situaciones imaginarias los niños lograron verse a través de los ojos de los demás, lo cual es un momento fundamental de la conciencia humana (Bajtin, 1997). Asimismo, en la comunicación conjunta que se generó en el juego los niños sintieron la necesidad de conocer los demás roles y de conocerse a sí mismos (Lisina, 1981).

El aporte innovativo que se expone en este artículo reside en que el mismo juego se vuelve complejo al enriquecer las situaciones imaginarias con el uso de diversos medios simbólicos. En efecto, es poco frecuente que en un aula de preescolar se dé la posibilidad de promover situaciones imaginarias con al apoyo de medios simbólicos materializados, perceptivos y verbales. Se concluye que los medios simbólicos materializados, perceptivos y verbales sirvieron de apoyo a la comprensión y expresión simbólica de los niños en el juego durante la creación de las situaciones imaginarias.

Agradecimientos: a la Dra. Yulia Solovieva, a la Dra. Milda Bredikyte, al Dr. Pentti Hakkarainen, a la Dra. Tatiana Akhutina, a la profesora Clemencia Cuervo Echeverry, a la Dra. Sonia de Zubiría. 


\section{REFERENCIAS}

Bajtin, M. (1997). Obras escogidas (Tomo 5: obras de 1940 - inicios de 1960). Moscú: Diccionarios Rusos.

Bredikyte, M. (2011). The Zones of Proximal Development in Children's play. University of Oulu, Finlandia.

Brill, F. (2004). Thinking outside the box: Imagination and Empathy beyond Story Writing. Literacy, 38, 83-89.

Diachenko, O. (2011). On Major Developments in Preschoolers' imagination. International Journal of Early Years Education, 19(1), 19-25.

Lisina, M. (1981). «La actividad de comunicación y su desarrollo». En: I. Iliasov, I., y V. Liaudis, V, Ya. Antología de la psicología pedagógica de las edades (pp. 125131). La Habana: Editorial Pueblo y Educación.

Galperin, P. (1981). «Sobre el método de formación por etapas de las acciones intelectuales». En: I. Iliasov, I., y V. Liaudis, Ya. Antología de la psicología pedagógica de las edades (pp. 125-131). La Habana: Editorial Pueblo y Educación.

Galperin, P. (1982). The psychology of thought and the theory of stepwise formation of mental operations. Moscú: Universidad Estatal de Moscú.

González-Moreno, C., y Solovieva, Y. (2014). Propuesta de método para el estudio de la formación de la función simbólica en la edad infantil. Tesis Psicológica, 9(2), 58-79.

González-Moreno, C. (2015). Formación de la función simbólica por medio del juego temático de roles sociales en niños preescolares. Rev. Fac. Med., 63(2), 235-41.

González-Moreno, C., y Solovieva, Y. (2015). Indicadores de adquisición de la función simbólica en el nivel de acciones materializadas en preescolares. Pensamiento Psicológico, 13(2), 79-94.

González-Moreno, C., Solovieva, Y., y Quintanar, L. (2016). Evaluación de adquisición de las acciones perceptivas simbólicas en niños preescolares de Bogotá, Colombia. Summa Psicológica UST, 13(1), 19-31.

González-Moreno, C. (2016). El juego de roles sociales como medio de formación de la función simbólica en niños preescolares (Tesis de doctorado). Universidad Iberoamericana de Puebla, México. 
González-Moreno, C. (2018). Actividad comunicativa interactiva en una experiencia de juego grupal con nińos en edad preescolar. Cuadernos Hispanoamericanos de Psicología, 17(2), 43-60.

Göncü, A. (1993). Development of Intersubjectivity in the Social Pretend Play of Young Children. Human Development, 36, 185-98.

Göncü, A., Jain, J., y Tuermer, U. (2007). «Children's Play as Cultural Interpretation». En: A. Göncü y S. Gaskins (eds.), Play and Development: Evolutionary, sociocultural, and Functional Perspectives (pp. 155-178). Mahwah, NJ: LEA.

Hakkarainen, P., y Bredikyte, M. (2015). "How Play Creates the Zone of Proximal Development». En: S. Robson S y S. Flannery S. (eds.), The Routledge International Handbook of Young Children's Thinking and Understanding (pp. 31-42). New York: Routledge.

Lindqvist, G. (1995). The Aesthetics of Play. A didactic Study of Play and Culture in Preschools. Sweden: Almqvist \& Wiksell International.

Lindqvist, G. (2003). Vygotsky's theory of creativity. Creativity Research Journal, $15(4), 245-251$.

Marjanovic-Shane, A., Ferholt, B., Miyazaki, K., Nilsson, M., Rainio, P., Hakkarainen, P., Pesic, M., y Beljanski-Ristic, L. (2011). «Play and Performance in Teaching and Teacher Education». En: C. Lobman y B. O’Neill. Play and Performance. Play \& Culture Studies, vol. 11 (pp. 3-32). United States: British Library.

Montealegre, R. (1998). El experimento formativo en el estudio del lenguaje egocéntrico. Revista Latinoamericana de Psicología, 30, 261-277.

Smith, M., y Mathur, R. (2009). Children's Imagination and Fantasy: Implications for Development, Education, and Classroom Activities. Research in the schools. Mid-South Educational Research Association, 16(1), 52-63.

Solovieva, Y., González-Moreno, C., y Quintanar, L. (2015). Indicators of Reflection during Acquisition of Symbolic Actions in Preschool Colombian Children. Psychology in Russia: State of the Art, 8(2), 61-72.

Solovieva, Y., González-Moreno, C., y Quintanar, L. (2016). Developmental Analysis of Symbolic Perceptual Actions in Preschools. British Journal of Education, Society \& Behavioural Science, 15(3), 1-13.

Solovieva, Y., y González-Moreno, C. (2016). Indicadores de adquisición de la función simbólica en el nivel de acciones verbales en preescolares. Rev. Fac. Med., 64(2), 257-265. 
Vigotsky, L. (1978). Mind and society. Cambridge, MA: Harvard University Press.

Vigotsky, L. (1995). Obras escogidas. Tomo III. Madrid: Visor.

Vigotsky, L. (2001). Obras escogidas. Tomo II. Madrid: Visor.

Vigotsky, L. (2007). La imaginación y el arte en la infancia. Madrid: Akal. 